\title{
ANÁLISE ESTRATÉGICA DA FERRAMENTA GERENCIAL DE SISTEMA DE BIBLIOTECAS ADOTADA NA BIBLIOTECA CENTRAL DA UNIVERSIDADE FEDERAL DO RIO GRANDE DO NORTE
}

\author{
Francisco Leonidas da Silva \\ Graduando em Administração \\ Curso de Administração \\ Universidade Federal do Rio Grande do Norte \\ leonidas.ifrn@live.com \\ Maria Aparecida da Silva \\ Graduando em Administração \\ Curso de Administração \\ Universidade Federal do Rio Grande do Norte \\ aparecida199220@hotmail.com \\ Aline Virgínia Medeiros Nelson \\ Doutora em Ciências Jurídicas \\ Professora do Departamento de Ciências Administrativas \\ Universidade Federal do Rio Grande do Norte \\ aline_nelson@hotmail.com
}

\begin{abstract}
Resumo
Atualmente o Sistema de Bibliotecas da Universidade Federal do Rio Grande do Norte (SISBI/UFRN) é constituído pela Biblioteca Central Zila Mamede (BCZM) e por 21 bibliotecas pertencentes à comunidade acadêmica federal. Nesse contexto, o artigo objetiva analisar a ferramenta gerencial SISBI mediante a eficiência do mecanismo de empréstimo de livros na BCZM, e especificamente, verificar se o sistema é de fato eficaz, e quais são os possíveis progressos nos procedimentos executados, na autonomia, na segurança da informação e na satisfação de seus usuários. A abordagem metodológica adotada foi o levantamento de dados bibliográficos e coleta das informações junto à obtenção de dados por meio de entrevista realizadas com colaboradores do setor de circulação da biblioteca, sendo servidores e funcionários terceirizados. Os resultados foram obtidos através da análise dos dados coletados, aplicados na matriz estratégica SWOT para destacar os principais fatores internos e externos que compõem o sistema. Com base nisso, foi possível identificar evolução e adaptação das bibliotecas universitárias em relação ao uso das tecnologias a fim de melhor atender às necessidades informacionais de seus usuários. Conclui-se que o SISBI possui eficiência nos serviços propostos, que passam por constantes inovações, além de contar com uma equipe preparada para eventuais problemas sistêmicos, como também garantindo a segurança do sistema.
\end{abstract}

Palavras-chave

Biblioteca universitária. SISBI/UFRN. Eficiência de serviços bibliotecários. Análise SWOT.

\section{INTRODUÇÃO}

Diante da grande inovação das tecnologias na gestão pública e da vasta demanda corrente no sistema de bibliotecas, é importante analisar a satisfações e os impactos destas para as organizações.

Nesse contexto, encontra-se o Sistema de Bibliotecas da Universidade Federal do Rio Grande do Norte (SISBI/UFRN). A regulamentação deste ocorreu em 05 de abril de 2013, através da Resolução No 004/2013CONSUNI e atende a todas as categorias de usuários da UFRN, sendo alunos do ensino fundamental, médio, técnico, graduação, pós-graduação, professores e funcionários, além da comunidade externa.

Atualmente, o SISBI/UFRN é constituído pela Biblioteca Central Zila Mamede (BCZM) e por 21 bibliotecas pertencentes à 
comunidade acadêmica federal, e tem como missão:

Promover o acesso à informação e oferecer suporte necessário ao desenvolvimento das atividades de ensino, pesquisa e extensão na UFRN. As unidades do SISBI são órgãos vitais no processo de ensino/aprendizagem, pesquisa e extensão no âmbito da universidade. Dentre umas das ferramentas mais importantes do SISBI está o mecanismo de empréstimo de exemplares realizado pelas bibliotecas. Os empréstimos são efetivados somente para os usuários que estão em absoluta regularidade com as bibliotecas e mediante apresentação da carteira de identidade ou de estudante, do crachá funcional, qualquer outro documento com foto, e através da senha do usuário que é cadastrado no SIGAA (PORTAL SISBI, 2017).

Os critérios adotados na Política de Empréstimos do SISBI levam em consideração as especificidades de cada categoria de usuário e do material informacional das bibliotecas, podendo sofrer modificações, além das diversas modalidades de empréstimos.

Nesse contexto, indaga-se qual a percepção dos administradores do SISBI e dos funcionários da Biblioteca Central em relação à satisfação e aos impactos ao ambiente organizacional, produzidos pelo sistema? Com essa questão em foco, será possível realizar a análise estratégica da ferramenta gerencial, a ponto de solucionar problemas e propor novas oportunidades ao SISBI.

Deste modo, este artigo tem como objetivo analisar estrategicamente a ferramenta gerencial SISBI mediante a satisfação e verificação do ambiente, quanto ao impacto de mecanismo de empréstimo de livros na BCZM/UFRN, sob a percepção dos administradores e de funcionários da biblioteca.

Nesse sentido, nos objetivos específicos pretende-se verificar se o sistema de empréstimos é considerado satisfatório perante a análise realizada e em que medida ele pode ser melhorado no tocante à eliminação do retrabalho, na autonomia, na segurança da informação e na satisfação das diferentes necessidades dos usuários.

A justificativa para escolha do tema deu-se em decorrência da instigação dos autores quanto à inovação na gestão pública, notadamente no aperfeiçoamento de ferramentas e técnicas gerenciais, no cumprimento das missões institucionais. Dentre estas, chamou-se a atenção para a ferramenta gerencial SISBI, objeto deste estudo.

No que concerne à originalidade, o principal destaque está na abordagem interdisciplinar entre Administração Pública e Ciências da Informação, possibilitada e construída pela escolha da metodologia, em que foi utilizada a ferramenta Matriz SWOT, para análise de ambiente, a fim de agregar o caráter estratégico à análise de conteúdo, o que apesar de não ser pioneiro nas Ciências Sociais Aplicadas, é, ainda, muito pouco utilizada.

Desta forma, o artigo oferta contribuição à área trabalhada, por possibilitar uma análise crítica e projetista em planejamento da gestão, não só para a organização analisada, mas também para outras que utilizem ferramentas semelhantes, no sentido de buscar a modernização e o aperfeiçoamento contínuo, pela perspectiva da análise de ambiente organizacional, em que esses sistemas são desenvolvidos e aplicados.

No que toca à verificação de originalidade quanto ao conteúdo, foi realizada uma busca na base de dados de artigos na Plataforma Scielo, em 09/06/2017. Utilizando-se a palavra "SISBI", nenhum resultado foi encontrado. Ao se procurar "Sistemas de Bibliotecas" foram localizados apenas um relato de experiência e um artigo, respectivamente, de 1998 de 2011, cujos títulos são: "Informatização da informação: a experiência do Sistema de Bibliotecas da Universidade Federal do Rio Grande do Sul" (GONÇALVES. et al, 1988); e "Imagem e percepção humana: alternativa aplicada na classificação da literatura infanto-juvenil de uma biblioteca escolar" (RAMOS. et al, 1988). Percebe-se que apenas o primeiro trata espe- 
cificamente de um sistema de bibliotecas de uma Instituição de Ensino Superior (IES).

A fim de ratificar os resultados desta busca, pesquisas semelhantes foram realizadas diretamente no portal deste periódico. Foram localizados três artigos, detectados com assuntos semelhantes a sistema de bibliotecas: um trata sobre fontes de informação em bibliotecas prisionais; outro sobre teorias de Ciências Sociais e Humanas que dialogam com a Biblioteconomia; e último sobre a usabilidade do formulário de catalogação (TONIN; SOUZA, 2014; TANUS, 2017; ZAMITE, 2016).

Portanto, nenhum dos três artigos detectados envolve análise sobre aspecto gerencial e estratégico no uso e aperfeiçoamento de ferramentas de sistemas de bibliotecas, corroborando-se com a relevância e originalidade, que justifica a escolha do tema.

$O$ artigo possui uma estrutura composta, além desta introdução, por referencial teórico, apresentação do caso, metodologia, análise de resultados, conclusão e referências.

\section{REFERENCIAL TEÓRICO}

No processo de construção do conhecimento, as bibliotecas, ao tratar, armazenar, organizar, sistematizar e facilitar o acesso e a recuperação da informação, como agente de transformação social, constituem elemento essencial para o desenvolvimento das atividades de ensino, pesquisa, extensão e inovação tecnológica, ou seja, contribuem para o progresso da ciência em sua forma ampla.

As IES são consideradas um ambiente propício e privilegiado para a produção e difusão deste conhecimento. Segundo Ohira (1998, p. 66),

Por intermédio das atividades de ensino, pesquisa e extensão, as universidades se voltam para a criação, a produção de conhecimento, e a busca do saber.

A universidade, para atender às demandas e expectativas informacionais da comunidade interna e externa, precisa ofere- cer a melhor infraestrutura e os melhores serviços. Werthein (2000) alerta que um dos grandes desafios advindos do avanço tecnológico é o de identificar o papel que estas inovações podem desenvolver no processo educacional e definir como utilizá-las para facilitar uma efetiva aceleração do processo de ensino e aprendizagem. Assim, o fatorchave do futuro será a capacidade da universidade e, em especial, de sua biblioteca assimilar os novos desafios, remover os obstáculos que as impedem de atender às necessidades de seus usuários (CUNHA, 2000) e buscar a melhoria continuada.

As bibliotecas universitárias têm vivenciado uma revolução interna em suas organizações, onde se processa uma inovação que visam facilitar o acesso e a disseminação da informação, tornando-as mais dinâmicas a fim de acompanhar as novas tendências e aprimorar a qualidade dos serviços informacionais e tecnológicos buscando a excelência.

Os sistemas integrados de bibliotecas são considerados

[...] uma alternativa prática de organização, possibilitando processos capazes de responder às demandas de flexibilidade, conectividade e descentralização das esferas contemporâneas de atuação e articulação social. (OLIVIERI, 2003).

A evolução tecnológica crescente na chamada Sociedade da Informação tem impactado diretamente no uso, no processamento, no armazenamento e na apropriação da informação. De certo modo, todos os setores que tem a informação como ativo acabam por ser modificados nesse cenário tecnológico. Com as bibliotecas universitárias não foi diferente, para atender às demandas dos usuários, passaram a perceber a crescente necessidade em utilizar recursos tecnológicos.

Os recursos de software proprietário são comumente utilizados por bibliotecas que possuem recursos financeiros para $o$ custeio e, diferentemente dos sistemas de paradigma livre, não possuem código aberto para adaptação. Com isso os profissionais da 
informação ficam vinculados às empresas para realizarem modificações em suas bibliotecas. O programa

[...] é fornecido sob licenciamento pago e sem o acesso ao códigofonte, ficando a implementação de melhoramentos ou alterações [dependentes] da visão, interesse e calendário da empresa fornecedora do software. (PARANHOS, 2004).

Segundo o Portal SISBI (2017), os serviços oferecidos pelas unidades que compõem o SISBI/UFRN estão ligados diretamente à promoção, à disseminação, ao uso das informações, e ainda à orientação aos usuários que são direcionados preferencialmente à comunidade acadêmica da UFRN. O SISBI oferece inúmeros serviços, nos quais se destacam:

Os serviços de Cadastro, Empréstimo Domiciliar (Regular, Especial e para Fotocópia), Renovação, Quitação, Comutação bibliográfica, Orientação bibliográfica e Auxílio ao usuário, Levantamento bibliográfico, Orientação à normalização de documentos, orientação à solicitação de Direitos Autorais, Catalogação na fonte e orientação nos Repositórios Digitais. Os serviços do sistema estão relacionados com o desenvolvimento, a preparação técnica e a organização das coleções que integram os acervos das bibliotecas (PORTAL SISBI, 2017).

Em relação ao acervo fornecido pelo SISBI, ele passa por constantes atualizações através da aquisição do material informacional por compra, doação e intercâmbio, que, segundo Portal SISBI (2017), é de acordo com a Política de Formação e Desenvolvimento de Coleções do SISBI/UFRN vigente.

O acesso às dependências das bibliotecas implica necessariamente a guarda de materiais particulares no guarda volumes, sem caracterizar constrangimento ao usuário. A consulta ao acervo é de livre acesso para a comunidade em geral, exceto às coleções especiais e o acervo de obras raras.

Afirma o Portal SISBI (2017) que poderão cadastrar-se nas bibliotecas somente os usuários definidos na Resolução do Conselho de Administração (CONSAD). O cadastro dar-se-á mediante a subscrição eletrônica do usuário no Sistema Integrado de Gestão de Atividades Acadêmicas (SIGAA), no menu Discente ou Módulo do Servidor Biblioteca - Cadastrar para Utilizar os Serviços da Biblioteca, devendo o interessado criar uma senha numérica com no mínimo 6 (seis) e no máximo 8 (oito) dígitos. Onde se caracterizam que:
Os usuários das bibliotecas, a co- munidade universitária e o público em geral, mas os empréstimos são liberados apenas para os usuários cadastrados. A comunidade univer- sitária é constituída pelos corpos docente, discente e técnico- administrativo da UFRN, não é permitida a retirada de publicações de qualquer unidade do SISBI, sem antes passar pelo serviço de em- préstimo, estando sujeito às san- ções disciplinares cabíveis, o extra- vio ou danificação das obras impli- cará em reposição ou substituição $\mathrm{da}(\mathrm{s})$ mesma(s), de acordo com o que estabelece o Título Perdas, Roubos ou Danos (PORTAL SIS- BI, 2017).

Segundo Dutra e Ohira (2004), o uso da informatização nas bibliotecas brasileiras é também tema de pesquisas realizadas com o objetivo de conhecer como ocorre este processo e quais os benefícios para os serviços e produtos oferecidos aos usuários. Destaca-se a pesquisa realizada por Burin, Lucas e Hoffman (2004) nas IES da Região Sul do país, que identificou os principais motivos para a informatização das bibliotecas universitárias, destacando-se a necessidade de ampliar a gama de serviços e produtos oferecidos, seguido da necessidade de baratear custos e agilizar processos.

Em uma pesquisa elaborada por Silva (2003, apud OLIVEIRA; SILVA, 2004), nas IES de Vitória (ES), os principais moti- 
vos apontados foram A necessidade de facilitar algumas funções do processamento técnico, o controle de circulação e a necessidade de disponibilizar serviços na Web.

A partir da revisão de bibliografia, do levantamento e da discussão das comunicações, averígua-se que a integração do sistema de bibliotecas é seguida na literatura e na organização estudada.

\section{APRESENTAÇÃO DO CASO}

A UFRN foi criada em 25 de junho de 1958, através de Lei Estadual, e federalizada em 18 de dezembro de 1960. Atualmente, a UFRN oferece 84 cursos de graduação presencial, 9 cursos de graduação à distância e 86 cursos de pós-graduação. Sua comunidade acadêmica é formada por mais de 37.000 estudantes (graduação e pósgraduação), 3.146 servidores técnicoadministrativos e 2 mil docentes efetivos, além dos professores substitutos e visitantes (UFRN, 2017).

É importante ressaltar a relevância que a universidade tem na vida da sociedade e no meio em que está inserida. Dentre os muitos projetos que são desenvolvidos dentro da academia, alguns são voltados a estimular o crescimento e a qualidade de vida da população como um todo.

A BCZM é uma unidade suplementar da UFRN diretamente subordinada à
Reitoria, que teve sua criação através da Resolução $\mathrm{N}^{\circ} 14$, emitida pelo Conselho Universitário, em 02 de maio de 1959. E foi considerado "Serviço Central de Biblioteca", que coordenava as atividades técnicas e administrativas das Bibliotecas das Faculdades Isoladas.

O acervo geral da BCZM, até abril de 2017, compreende um total de mais de 420.291 volumes, distribuídos em exemplares e fascículos, ou seja, livros, folhetos, periódicos, teses, dissertações e multimeios das diversas áreas do conhecimento. Além disso, disponibiliza à comunidade universitária acesso a 3.536 livros digitais distribuídos nas mais diferentes áreas (UFRN/SISBI, 2017).

A BCZM é o órgão central executivo do SISBI/UFRN, responsável pela coordenação, pelo planejamento e pela fiscalização das atividades técnicas das unidades de informação que compõem esse Sistema. O SISBI compõe vários serviços a ser oferecidos para o público, com fundamento em uma política totalmente regulamentada, com normas e padrões a serem distinguidos (UFRN/SISBI, 2017).

Segundo ainda a UFRN/SISBI (2017), em relação à Política de Empréstimos do SISBI, os critérios adotados levam em consideração as especificidades de cada categoria de usuário e do material informacional como mostra os Quadros 1 a 3.

Quadro 1 - Categorias da Biblioteca da UFRN e de outras instituições

\begin{tabular}{|c|c|c|c|c|c|c|}
\hline $\begin{array}{c}\text { Tipo de } \\
\text { Empréstimo }\end{array}$ & $\begin{array}{l}\text { Tipo de } \\
\text { material }\end{array}$ & Suporte & Status & Quantidade & Prazo & Renovação \\
\hline $\begin{array}{c}\text { Entre } \\
\text { bibliotecas }\end{array}$ & Livro & Impresso & Regular & 03 & 30 dias & - \\
\hline Personalizado & Livro & Impresso & $\begin{array}{l}\text { Especial } \\
\text { e/ou } \\
\text { regular }\end{array}$ & $\begin{array}{l}\text { A definir pela } \\
\text { unidade }\end{array}$ & $\begin{array}{l}\text { A definir } \\
\text { pela } \\
\text { unidade }\end{array}$ & - \\
\hline \multicolumn{7}{|c|}{$\begin{array}{l}\text { Material fora de empréstimo: coleções com status "não circula" - Zila Mamede, obras raras, folhetos de cordel e autores norterio- } \\
\text { grandenses - ou quaisquer outros documentos que, pela importância, constante procura ou natureza, não podem ser empresta- } \\
\text { dos. }\end{array}$} \\
\hline
\end{tabular}

Fonte: SISBI/UFRN (2017).

Em relação ao serviço de renovação, essa modalidade permite que as obras retiradas por empréstimo domiciliar sejam renovadas uma única vez, pelo mesmo prazo. Após o término desse prazo, as obras so- mente poderão sair para novo empréstimo após 24 horas.

A devolução do material informacional emprestado pelas bibliotecas deve ser realizada, dentro do prazo estabelecido, conforme data indicada na papeleta anexada no 
final do documento e/ou enviada automaticamente por e-mail. Os usuários em débito com as bibliotecas receberão aviso de cobrança, por e-mail, um dia após o vencimento do prazo de devolução do material informacional e, ainda, semanalmente, até ser efetivada a devolução (UFRN/SISBI, 2017).

Quadro 2 - Categoria aluno de graduação regular e especial, de curso técnico / servidores

\begin{tabular}{|c|c|c|c|c|c|c|}
\hline $\begin{array}{c}\text { Tipo de Em- } \\
\text { préstimo }\end{array}$ & Tipo de material & Suporte & Status & Quantidade & Prazo & Renovação \\
\hline \multirow{3}{*}{ Normal } & $\begin{array}{c}\text { Livro impresso ou em } \\
\text { CD-ROM }\end{array}$ & $\begin{array}{c}\text { Papel e CD- } \\
\text { ROM }\end{array}$ & Regular & 03 & 15 dias & 01 \\
\hline & Suplemento & $\begin{array}{c}\text { Impresso, } \\
\mathrm{CD}, \mathrm{DVD} \text { e } \\
\text { vídeo }\end{array}$ & Regular & 03 & 15 dias & 01 \\
\hline & Disco e partitura & Disco e CD & Regular & 03 & 15 dias & 01 \\
\hline Especial & $\begin{array}{l}\text { Livro, suplemento, tese, } \\
\text { anais de evento, periódi- } \\
\text { co, folheto dissertação, } \\
\text { multimeios (CD, DVD, } \\
\text { vídeo, slides, cassete, } \\
\text { microficha e microfilme, } \\
\text { mapa, fotografia, parti- } \\
\text { tura e monografia }\end{array}$ & $\begin{array}{l}\text { Impresso, } \\
\text { vídeo, mapa, } \\
\text { CD, DVD, } \\
\text { cassete, } \\
\text { fotografia, } \\
\text { slide, disco, } \\
\text { microficha e } \\
\text { microfilme } \\
\end{array}$ & $\begin{array}{c}\text { Especial } \\
\text { e/ou } \\
\text { regular }\end{array}$ & 03 & 01 dia & - \\
\hline Fotocópia & $\begin{array}{c}\text { Livro, suplemento, } \\
\text { dicionário, tese, anais de } \\
\text { evento, folheto, periódi- } \\
\text { co, partitura, dissertação } \\
\text { e monografia }\end{array}$ & Impresso & $\begin{array}{c}\text { Especial } \\
\text { e/ou } \\
\text { regular }\end{array}$ & 02 & 03 horas & - \\
\hline
\end{tabular}

Fonte: SISBI/UFRN (2017).

Quadro 3 - Categoria aluno de pós-graduação regular e especial / professor / usuário externo

\begin{tabular}{|c|c|c|c|c|c|c|}
\hline $\begin{array}{l}\text { Tipo de Em- } \\
\text { préstimo }\end{array}$ & Tipo de material & Suporte & Status & Quantidade & Prazo & Renovação \\
\hline \multirow{3}{*}{ Normal } & $\begin{array}{c}\text { Livro impresso ou em } \\
\text { CD-ROM }\end{array}$ & $\begin{array}{l}\text { Papel e CD- } \\
\text { ROM }\end{array}$ & Regular & 05 & 30 dias & 01 \\
\hline & Suplemento & $\begin{array}{l}\text { Impresso, } \\
\text { CD, DVD e } \\
\text { vídeo }\end{array}$ & Regular & 05 & 30 dias & 01 \\
\hline & Disco e partitura & Disco e CD & Regular & 05 & 30 dias & 01 \\
\hline Especial & $\begin{array}{l}\text { Livro, suplemento, tese, } \\
\text { anais de evento, periódi- } \\
\text { co, folheto dissertação, } \\
\text { multimeios (CD, DVD, } \\
\text { vídeo, slides, cassete, } \\
\text { microficha e microfilme, } \\
\text { mapa, fotografia, parti- } \\
\text { tura e monografia }\end{array}$ & $\begin{array}{l}\text { Impresso, } \\
\text { vídeo, mapa, } \\
\text { CD, DVD, } \\
\text { cassete, } \\
\text { fotografia, } \\
\text { slide, disco, } \\
\text { microficha e } \\
\text { microfilme }\end{array}$ & $\begin{array}{c}\text { Especial } \\
\text { e/ou } \\
\text { regular }\end{array}$ & 03 & $01 \mathrm{dia}$ & - \\
\hline Fotocópia & $\begin{array}{c}\text { Livro, suplemento, } \\
\text { dicionário, tese, anais de } \\
\text { evento, folheto, periódi- } \\
\text { co, partitura, dissertação } \\
\text { e monografia }\end{array}$ & Impresso & $\begin{array}{c}\text { Especial } \\
\text { e/ou } \\
\text { regular }\end{array}$ & 02 & 03 horas & - \\
\hline
\end{tabular}

Fonte: SISBI/UFRN (2017).

Em caso de perdas, roubos e/ou danos causados ao patrimônio das bibliotecas, o usuário responderá a um processo administrativo conforme sanções disciplinares regulamentadas no Regimento da UFRN e no Código Penal Brasileiro, no que se refere ao dano ao Patrimônio Público, e só será possível emitir a declaração de quitação quando o usuário não tiver mais nenhum débito com a biblioteca, uma vez que é um dos documentos obrigatórios para fins de trancamento de programa, colação de grau e emissão de diploma de conclusão de curso. Essa declaração é concedida somente para o 
usuário que não possuir empréstimos em aberto em todas as bibliotecas do SISBI.

Todo processo da realização dos empréstimos dos exemplares está contido no sistema de informação do SISBI. Assim, nenhuma das etapas pode ser ultrapassada, uma vez que no sistema contém todos os registros de informações do acervo, que vai desde o cadastro dos livros até o processo de empréstimos e devoluções. É, portanto, fundamental que o sistema esteja constantemente atualizado e permita a rápida visualização das informações demandadas.

De acordo com Zamite (2016), a biblioteca também tende a se adaptar aos às novidades e aos avanços tecnológicos. Assim, a automação veio para suprir as necessidades do bibliotecário na era tecnológica. O bibliotecário precisa conhecer esta ferramenta para dinamizar suas atividades e proporcionar agilidade no atendimento.

Neste artigo é estudado, principalmente, o software que compõe o SISBI. Conforme Laudon e Laudon (2010), a tendência de software mais influente é o movimento pelo código aberto, que é desenvolvido por uma comunidade de programadores ao redor do mundo que disponibilizam seus programas aos usuários sob um dos vários esquemas de licença disponíveis.

Assim, o profissional bibliotecário deverá ser capacitado para que possa utilizar corretamente as ferramentas tecnológicas no amplo do seu conhecimento teórico para aplicá-las na prática com eficácia em seu trabalho. (SOUZA, 2013). Tendo sido apresentado o caso, segue a apresentação da metodologia.

\section{METODOLOGIA}

Para atender aos objetivos do estudo, foi realizada uma pesquisa de caráter descritiva com enfoque analítico qualitativo, por técnica de estudo de caso. A realização da pesquisa ocorreu no período de abril a maio de 2017 e revista em outubro do mesmo ano, com foco no mecanismo de empréstimos de exemplares de livros adotados pela BCZM/UFRN, em que foram analisados os pontos fortes e fracos do sistema como também identificadas às oportunidades e ameaças, tendo por enfoque a percepção dos funcionários da biblioteca, no aspecto gerencial.

Para a coleta de informações e obtenção de dados, além da observação em campo, foram realizadas entrevistas semiestruturadas com colaboradores do Setor de Circulação da Biblioteca. Nesse sentido, como feito por Silva e Araújo (2016), para a seleção da amostra foi realizado um trabalho de observação in loco na BCZM no horário de funcionamento, sendo percebido a frequência e os usuários, sendo estes: usuários da biblioteca analisada, funcionários das bibliotecas e gestor da Secretária de Educação. Após essa observação, foram realizadas as entrevistas com os dois últimos grupos.

Desse modo, a entrevista foi realizada com seis pessoas, sendo dois servidores, administradores da ferramenta, e quatro funcionários terceirizados que trabalham diretamente com o sistema. Deve ser dito, ainda que, antes da entrevista, foi explicado a cada um dos entrevistados os objetivos da pesquisa, bem como sobre a manutenção do anonimato do respondente.

A escolha da amostra justificou-se, ainda, porque os servidores entrevistados estiveram presentes no processo de elaboração e implantação do sistema SISBI. As entrevistas realizadas tiveram a finalidade de coletar informações sobre o sistema, notadamente, no que diz respeito ao seu manuseio, buscando identificar as facilidades e dificuldades apresentadas na percepção dos entrevistados, distribuindo-os em dois grupos, conforme Quadro 4.

Após a coleta de informações, os dados foram organizados, tendo por base a matriz SWOT, que pode ser explicada da seguinte forma:

A ferramenta de análise conhecida como matriz SWOT refere-se à abreviatura de Strengths (Forças), Weaknesses (Fraquezas), Opportunities (Oportunidades) e Threats (Ameaças), que tem a finalidade de avaliar os ambientes internos e externos, possibilitando a formulação e proposição de estratégias de melhoria. (SILVA; NEVES; NEVES, 2016). 
Quadro 4 - Roteiros de entrevistas aplicados

\begin{tabular}{|l|l|}
\hline $\begin{array}{l}\text { Roteiro de perguntas iniciais aplicadas somente aos } \\
\text { administradores do sistema (Entrevistados 01 e 02) }\end{array}$ & $\begin{array}{l}\text { Roteiro de pergunta introdutória aplicadas somente } \\
\text { aos funcionários (Entrevistados 03, 04, 05, 06) }\end{array}$ \\
\hline $\begin{array}{l}\text { 1. O que diferencia essa atual ferramenta da que } \\
\text { existia anteriormente? Você considera uma } \\
\text { evolução? }\end{array}$ & $\begin{array}{c}\text { 1. Qual o seu principal manuseio da ferramenta } \\
\text { SISBI? }\end{array}$ \\
$\begin{array}{l}\text { 2. } \quad \begin{array}{l}\text { Foi feito algum planejamento estratégico antes } \\
\text { da construção da ferramenta? }\end{array} \\
\text { 3. Já foi realizado algum trabalho sobre o SISBI? }\end{array}$ \\
\hline Roteiro de perguntas comuns aplicadas aos dois grupos de entrevistados \\
\hline 1. Quais os pontos positivos e os negativos? \\
2. Há sugestões de melhorias quanto à autonomia na segurança da informação e na satisfação das necessida- \\
3. Cos dos usuários. \\
40), você considera o SISBI é eficaz? \\
4. Como você analise o manuseio do SISBI? \\
5. O SISBI atende as expectativas da demanda?
\end{tabular}

Fonte: Elaborado pelos autores (2017).

Deve ser dito, ainda, que a matriz SWOT, quando aplicada avaliação crítica das capacidades internas (nível/micro), aponta potencialidades e deficiências, o que significa que são variáveis controláveis pela organização, indicando qual posição atual desta ou do projeto. Já no ambiente externo (ní$\mathrm{vel} / \mathrm{macro})$, são verificadas as oportunidades e ameaças, entendidas como variáveis não controláveis, possibilitando antecipar pontos de impactos positivos e negativos, em um cenário futuro (OLIVEIRA, 2006).

Apesar de ser inovadora, a matriz SWOT como técnica para aprimorar a análise de conteúdo ou de discurso, em âmbito de metodologia da pesquisa, não é algo inédito, pois já foi utilizada em artigos científicos de diversas áreas, objetivando construir diagnósticos sobre o ambiente e a visão estratégica dos sujeitos envolvidos. (PASSETTI et al., 2016; NAVARRO; ALENCAR, 2016; SABBAG; COSTA, 2015; SILVA; NEVES; NEVES, 2016; AMBROS; GONÇALEZ; ANGELO, 2012), o que se ajusta ao objetivo geral deste artigo.

Nesta perspectiva, utilizou-se a SWOT a fim de construir a análise sobre a satisfação da ferramenta, tendo por base uma visão estratégica dos sujeitos e os impactos no ambiente organizacional.

No tocante às etapas da pesquisa, primeiramente, foram realizados levantamentos bibliográficos com o intuito de apre- sentar informações a respeito da UFRN, da BCZM para formar uma base conceitual e chegar ao objeto de estudo, o SISBI.

Em seguida, foi verificada através da entrevista e observação, a funcionalidade do sistema de empréstimos, pelos usuários internos e externos ao sistema, que são os funcionários e estudantes da instituição, sendo a entrevista aplicada somente aos primeiros. A partir do levantamento de dados, realizou-se a análise do conteúdo pela ferramenta matriz SWOT e respectiva análise desta.

\section{ANALÍSE E RESULTADOS}

Através da descrição dos processos desempenhados no sistema ERP e pela observação e análise do estudo de caso, podese constatar que, com a busca de excelência na gestão, para que uma organização pública possa destacar-se e manter sua posição, o sistema utilizado para gerir a cadeia de suprimentos e de valor tem atualmente um grau de importância bastante elevado.

É possível destacar diversos pontos em relação à utilização do sistema na empresa, dispondo das suas características numa análise de SWOT. Sobre essa perspectiva a análise que segue aborda os pontos descritos no Quadro 5 de acordo com a realidade da organização estudada.

Através da descrição dos processos desempenhados no sistema SISBI e pela 
observação e análise dos resultados obtidos na entrevista, foi possível identificar evolução e adaptação das bibliotecas universitárias em relação ao uso das tecnologias quando se compara à tecnologia anteriormente utiliza$\mathrm{da}$, a fim de melhor atender às necessidades informacionais de seus usuários.

Segundo o Entrevistado 01, a atual Ferramenta SISBI é empregada para a realização de empréstimos e devolução de exemplares da UFRN, tendo como objetivo atender à comunidade acadêmica, disponibilizando o acervo aos seus usuários. O sistema de bibliotecas é de suma relevância como fonte de informação para as comunidades interna e externa à academia.

Nesse sentido, segundo o Entrevistado 02, a principal diferença do atual SISBI para o sistema adotado anteriormente foi com relação à administração dos serviços e dos recursos humanos. O Sistema anterior não era formalizado quanto à distribuição dos cargos, então, os bibliotecários eram lotados na Biblioteca Central e transferidos às Bibliotecas Setoriais, o que dificultava o monitoramento da gestão central, ocasionando retrabalho e prejuízos em termos de comunicação. Após o SISBI, os servidores bibliotecários passaram a ser lotado nos próprios Centros de Ciências, também chamados de Unidades Especializadas, o que formalizou uma situação de descentralização que já existia e facilitou muito o controle administrativo, o que por si só já significou uma grande evolução.

No tocante à indagação sobre a realização planejamento estratégico para construção do SISBI, os Entrevistados 01 e 02 responderam afirmativamente. Segundo as entrevistas, após a decisão de que a atual ferramenta seria concebida, foi designada uma comissão para fazer um levantamento sobre o conjunto de bibliotecas da UFRN, bem como sobre o que seria necessário quanto à estrutura organizacional. Nas palavras do Entrevistado 02:

Nesta comissão designada tiveram estudos da quantidade de bibliotecas existentes; como se manteria e qual seria a estrutura organizacional do Sistema, até para analisar a ques- tão de recursos orçamentários e sua distribuição".

Além disso, foi relatado que no planejamento estratégico foram realizadas visitas técnicas nos Centros de Ciências, a fim de analisar bibliotecas já instaladas e também para verificar a possibilidade de abertura de outras, bem como a definição de modelos de padronização de qualidade para as bibliotecas setoriais. Essa expansão da rede de bibliotecas setoriais e a inovação quanto à gestão e busca de modelos de excelência corroboram com a percepção da evolução positiva do SISBI, quando comparado ao sistema anterior.

Também foi constatado que essas mudanças despertaram interesse em pesquisadores. De acordo com os Entrevistados 01 e 02 , já foram feitos alguns trabalhos acadêmicos e atualmente estão sendo desenvolvidas algumas dissertações de mestrado sobre o SISBI, mas tratando de enfoques muito específicos, como comprometimento organizacional, comunicação e desenvolvimento do sistema, mas nenhum dos trabalhos com o enfoque deste, o que reforça a justificativa sobre a originalidade e a importância deste tema.

Quanto à pergunta introdutória para os funcionários (Entrevistados 03, 04, 05, 06), todos disseram trabalhar com a Ferramenta SISBI, tendo como principal função realização de empréstimos e devolução de exemplares da UFRN. Esse foi o principal critério para a escolha destes sujeitos como entrevistados, a fim de ouvi-los quanto à análise da satisfação e a percepção quanto aos impactos dela no ambiente organizacional.

Após o levantamento de dados iniciais, passou-se para análise de conteúdo para construção da ferramenta SWOT, que, conforme já esclarecido na metodologia, é uma técnica que sintetiza os principais fatores internos e externos das organizações e sua capacidade estratégica de influenciar uma tendência de causar maior impacto no desenvolvimento organizacional (JOHNSON, et al., 2007). O objetivo desta ferramenta 
[...] é identificar o grau em que as forças e fraquezas atuais são relevantes para, e capazes de, lidar com as ameaças ou capitalizar as oportunidades no ambiente da organização." (JOHNSON et al., 2007).

Mediante a análise de conteúdo das entrevistas realizadas, notadamente, quanto às perguntas 1 e 2 do Roteiro de perguntas comuns, foram categorizados como "oportunidades" e "forças", o conteúdo apontado como critérios positivos e às sugestões de melhorias, quanto ao ambiente externo e interno da Biblioteca Central, respectivamente. Já como "ameaças" e "fraquezas", os critérios considerados negativos, quanto ao ambiente externo e interno, respectivamente.

Explica-se, ainda, que o controle é classificado quanto à esfera de governabilidade, a qual é explicada por Carlos Matus (1991, p. 30) da seguinte forma:
O governante real, como condutor de situações, situa-se entre os dois extremos. O equilíbrio entre as variáveis que controla e as que não controlam define sua governabilidade.

Nesse contexto, esclarece-se, ainda, que foi delimitado como ambiente interno a Biblioteca Central, em que a esfera de governabilidade foi mensurada, conforme as competências institucionais da Direção, que é o órgão maior dentro da estrutura organizacional, conforme Resolução $\mathrm{N}^{\circ} 14$, emitida pelo Conselho Universitário da UFRN, em 02 de maio de 1959.

Como resultado, foram destacados os seguintes dados, classificados e distribuídos no quadro da análise SWOT, a fim de se construir o diagnóstico do ambiente, na percepção subjetiva dos entrevistados, conforme Quadro 5.

Quadro 5 - Roteiros de entrevistas aplicados

\begin{tabular}{|c|c|}
\hline \multicolumn{2}{|c|}{ Matriz de Análise SWOT } \\
\hline Oportunidades & Ameaças \\
\hline $\begin{array}{l}\text { - } \quad \text { Abertura para possíveis parcerias; } \\
\text { - } \quad \text { Tecnologias avançadas; } \\
\text { - } \quad \text { Otimização do sistema para autos procedimentos; } \\
\text { - } \quad \text { Surgimento de canais de comunicação. }\end{array}$ & $\begin{array}{l}\text { - Falta de conscientização dos usuários; } \\
\text { - Novas demandas. }\end{array}$ \\
\hline $\begin{array}{l}\text { - Regimento interno rígido do setor de circulação, } \\
\text { - } \quad \text { Tuanto à realização de empréstimo; } \\
\text { - } \quad \text { Aplicativo de acesso ao acervo; } \\
\text { - } \quad \text { Integração das bibliotecas da UFRN; } \\
\text { - } \quad \text { Autonomia do usuário em realizar renovações de } \\
\text { - } \quad \text { Sistemplares; }\end{array}$ & $\begin{array}{l}\text { - Exemplares indisponíveis fisicamente, mas } \\
\text { disponíveis no sistema; } \\
\text { - } \quad \text { Falta de divulgação sobre as inovações do } \\
\text { sistema; } \\
\text { - Não disponibilidade de reserva de material } \\
\text { - Suspés do SIGAA. } \\
\text { - Suspensão de empréstimos quando há fa- } \\
\text { lhas no sistema. }\end{array}$ \\
\hline Forças & Fraquezas \\
\hline
\end{tabular}

Fonte: Elaborado pelos autores (2017).

A interação do ambiente interno com o ambiente externo, citados nos conceitos da análise SWOT, traz um demonstrativo dos níveis de qualificação da organização e aponta seus índices de competitividade perante a sociedade. A análise dos dados pesquisados, bem como o destaque dos pontos relevantes indicam os pontos que serão decisivos para o desenvolvimento de uma estra- tégia que busca o desenvolvimento da organização analisada. (ANDRADE et al., 2008).

Partindo-se desta perspectiva, segun-

do os Entrevistados, as forças do sistema estão relacionadas principalmente a sua autonomia. Verifica-se que o mesmo está sempre se adaptando diante do crescimento tecnológico. O sistema é claro em relação aos objetivos, e as falhas encontradas são mínimas, e, quando identificadas, são rapidamen- 
te solucionadas pela equipe de Tecnologia da Informação (TI) da UFRN, a Superintendência de Informática.

Embora se tenha notado eficiência após a criação do sistema e, por ventura, o manuseio e a inovação, são necessários à melhoria contínua do referido sistema em função da aceleração no processo de aprendizagem, conforme foi visto em Werthein (2000) e Cunha (2000).

O grau de satisfação dos colaboradores que manuseiam o SISBI no processo de empréstimo e devoluções de livros é bastante alta. Mediante os dados coletados pelas entrevistas, observou-se que foi apontado por todos os entrevistados que a ferramenta é eficaz, o sistema é de fácil manuseio e atende às demandas esperadas. Caso ocorra algum problema sistêmico é acionada uma equipe especializada de TI da própria Universidade para os devidos reparos. Isso foi considerada uma oportunidade.

O sistema de empréstimo é o único instrumento que é utilizado para a atividade fim. Quando há problemas técnicos não há a possibilidade de realizações de empréstimos, os usuários devem aguardar a solução do problema e isso foi considerado como uma fraqueza.

A pesquisa traz como sugestão de melhoria para o sistema de empréstimo, como propõe Cunha (2000), a criação de uma ferramenta dentro do SISBI que proporcionaria o auto empréstimo e auto devolução dos exemplares, permitindo aos usuários realizar estas atividades via sistema. $\mathrm{O}$ sistema proporcionaria a leitura do código de barras dos livros e, após análise da disponibilidade do material no acervo, seria exibida a tela de dados do usuário para a digitação de login e senha, mediante a confirmação dos dados o sistema geraria um comprovante de empréstimo que o usuário deveria mostrar ao responsável que iria desmagnetizar o livro, e verificar se realmente a liberação foi concluída. O mesmo processo aconteceria para a devolução dos livros.

Tem-se também como oportunidade a integração direta com os usuários do sistema, trazendo mais informações que possam deixar os seus usuários mais atentos às regras, como também por dentro das novidades e inovações que facilitam o acesso e despertam o interesse de seu público alvo, assim, facilitando o processo de ensino mencionado por Werthein (2000).

A integração realizada entre os setores que compõem o grupo da BCZM foi o fator principal na criação do sistema de bibliotecas, garantindo maior eficiência, fazendo ênfase ao que foi questionado por OLIVIERI (2003).

A UFRN criou o SISBI como forma de reduzir custos que eram pagos aos fornecedores do sistema utilizado anteriormente, também com o intuito de vincular as informações de suas bibliotecas, oferecendo acesso direto ao sistema, comparando a abordagem feita por Paranhos (2004).

Em contrapartida, é importante ficar atento às ameaças que o sistema pode sofrer de fora, bem como manter uma equipe de TI especializada e preparada para possíveis invasões no sistema, como também para resolver quaisquer problemas inesperados de software.

\section{CONCLUSÃO}

A implantação do SISBI, além de promover a integração entre as bibliotecas, trouxe novos mecanismos para o sistema de empréstimo, devolução e renovação de livros, causando a substituição do sistema anteriormente utilizado pela BCZM, o qual foi de grande relevância no que se refere à praticidade de manuseio do software, agilidade das informações vinculadas e relatórios gerenciais das demandas do sistema, comprovando assim a sua eficiência.

Nos resultados descritos diante da análise estratégica SWOT, observou-se que as fraquezas podem ser facilmente resolvidas, sendo raras as ocorrências de falha sistêmica, apesar de não possuírem um segundo plano, ou seja, outro sistema, a ferramenta dispõe de uma equipe preparada para atender a quaisquer transtornos referente à tecnologia da informação, como também garantindo a segurança do sistema em relação a hackers. Além disso, não são comuns acontecer erros no acervo disponibilizado e, 
caso ocorra, também são fáceis de solucionar.

Nas entrevistas que foram realizadas com os administradores e funcionários, foi possível verificar através da averiguação crítica a eficiência e a eficácia do sistema, que foram diagnosticadas na análise estratégica dos ambientes interno e externo.

Assim, constatou-se pela análise subjetiva dos sujeitos entrevistados uma percepção bem mais positiva do que negativa, haja vista o reconhecimento e a boa aceitação da ferramenta e o olhar otimista quanto a um maior número de oportunidades.

Ainda se sugeriu uma otimização do sistema, implementando a modalidade de autoatendimento, fazendo com que haja redução de gastos e despesas com funcionários e ferramentas que auxiliam no empréstimo e na devolução, modelo já usado em outras bibliotecas, tanto públicas como privadas.

Por todo exposto, concluiu-se que essa projeção positiva de um cenário para o aperfeiçoamento da SISBI foi ratificado pelo aperfeiçoamento contínuo integrado a outros setores da Universidade, notadamente aos vinculados aos sistemas de informação, como a Superintendência de Informática e os Centros de Ciências, o que traça um panorama positivo para o crescimento tecnológico e a busca de soluções inovadoras para melhoria na prestação de serviços da organização analisada.

\title{
STRATEGIC ANALYSIS OF THE LIBRARY SYSTEM MANAGEMENT TOOL ADOPTED IN THE CENTRAL LIBRARY OF THE FEDERAL UNIVERSITY OF RIO GRANDE DO NORTE
}

\begin{abstract}
Currently, the Library System of the Federal University of Rio Grande do Norte (SISBI/UFRN) consists of the Zila Mamede Central Library (BCZM) and 21 libraries belonging to the federal academic community. In this context, the article aims to analyze the SISBI management tool through the efficiency of the book loan mechanism in BCZM, and specifically to verify if the system is indeed effective, and what are the possible progress in the executed procedures, Autonomy, information security and the satisfaction of its users. The methodological approach adopted was the collection of bibliographical data and the collection of information along with obtaining data through an interview with collaborators of the circulation sector of the library, being servers and outsourced employees. The results were obtained through the analysis of the collected data, applied in the SWOT strategic matrix to highlight the main internal and external factors that make up the system, based on this, it was possible to identify evolution and adaptation of the university libraries in relation to the use of the technologies in order to better serve the informational needs of its users. in which it was concluded that the SISBI has efficiency in the proposed services, where they undergo constant innovations, besides having a team prepared for possible systemic problems, as well as guaranteeing the security of the system.
\end{abstract}

Keywords

University library. SISBI/UFRN. Efficiency of library services. SWOT Analysis. Artigo recebido em 19/06/2017 e aceito para publicação em 28/06/2018

\section{REFERÊNCIAS}

AMBROS, J. D'; GONÇALEZ, J. C.; ANGELO, H. Contribuições à implantação de polo moveleiro na Região Central do Tocantins. CERNE, Lavras, v. 18 n. 3, jul./set. 2012. Disponível em: $<$ http://dx.doi.org/10.1590/S0104$77602012000300004>$. Acesso em: 03 out. 2017.
ANDRADE, J. C. et al. Aplicação da análise SWOT para identificar oportunidades para o desenvolvimento econômico e social. In: ENCONTRO LATINO AMERICANO DE INICIAÇÃO CIENTÍFICA, 9., 2008, Cruzeiro. Anais... Cruzeiro: Universidade do Vale do Paraíba; 2008.

BURIN, C. K.; LUCAS, E. R. O.; HOFFMANN, S. G. Informatizar por quê? A experiência das bibliotecas universitárias 
informatizadas na Região Sul. In: SEMINÁRIO NACIONAL DE BIBLIOTECAS UNIVERSITÁRIAS, 13.,17-21 out. 2004, Natal. Anais... Natal: UFRN, 2004. Disponível em:

$<$ https://www.pergamum.pucpr.br/redeper gamum/trabs/Camila_K_Burin-

Informatizar_por_que.pdf $>$. Acesso em: 03 out. 2017.

CUNHA, M. B. Construindo o futuro: a biblioteca universitária brasileira em 2010. Ciência da Informação, Brasília, v. 29, n. 1, p. 71-80, jan. /abr. 2000.

DUTRA, A. K. F.; OHIRA, M. L. B. Informatização e automação de bibliotecas: análise das comunicações apresentadas nos seminários nacionais de bibliotecas universitárias (2000, 2002 e 2004). Informação \& Informação, v. 9, n. 1, p. 01-23, 2004. Disponível em:

$<$ http://www.brapci.ufpr.br/brapci/v/a/60 62>. Acesso em: 03 out. 2017.

FRANÇA, M. N.; CARVALHO, A. M. G. Sociedade da Informação e Biblioteca Universitária: Contribuições para a Democratização do Acesso ao Conhecimento. In: XVI ENCONTRO NACIONAL DE PESQUISA EM CIÊNCIA DA INFORMAÇÃO, 16., 2015, João Pessoa. Anais... João Pessoa: PPGCI/UFPB, 2015. Disponível em: <http://www.ufpb.br/evento/lti/ocs/index .php/enancib2015/enancib2015/paper/vie wFile 3012/1120>. Acesso em: 01 maio 2017.

GONÇALVES, E. et al. Informatização da informação: a experiência do Sistema de Bibliotecas da Universidade Federal do Rio Grande do Sul. Ciência da Informação, Brasília, v. 27, n. 1, p. 99-102, jan./abr. 1998. Disponível em:

$<$ http://www.scielo.br/pdf/ci/v27n1/14.p df>. Acesso em: 10 jun. 2017.

JOHNSON, G.; SCHOLES, K.; WHITTINGTON, R. Explorando a estratégia corporativa. 7. ed. Porto Alegre: Bookman, 2007.
LAUDON, K.; LAUDON, J. Sistemas de informação gerenciais. 9. ed. São Paulo: Pearson Prentice Hall, 2010.

MATUS, C. O plano como aposta. São Paulo em perspectiva, São Paulo, v. 5, n. 4, p. 28-42, out/dez. 1991. Disponível em: $<$ http://produtos.seade.gov.br/produtos/sp p/v05n04/v05n04_07.pdf>. Acesso em: 05 out. 2017.

NAVARRO, F. A. R.; ALENCAR, C. Análise dos elementos estratégicos em processos de internacionalização: empresas brasileiras de real estate visando ao mercado residencial da Costa Rica. Ambiente construído, Porto Alegre, v. 16, n.1, jan./mar. 2016. Disponível em: < http://dx.doi.org/10.1590/s1678$86212016000100074>$ Acesso em: 05 out. 2017.

OHIRA, M. L. B. Por que fazer pesquisa na Universidade? Revista ACB: Biblioteconomia em Santa Catarina, Florianópolis, v. 3, n. 3, p. 65-76, 1998.

OLIVEIRA, D. P. R. Planejamento estratégico: conceitos, metodologia, práticas. 10. ed. São Paulo: Atlas, 2006.

OLIVEIRA, E.; SILVA, R. H. Avaliação de software para bibliotecas: um estudo de caso com o Gnuteca. In: SEMINÁRIO NACIONAL DE BIBLIOTECAS UNIVERSITÁRIAS, 13., 2004, Natal. Anais... Natal, RN: Universidade do Rio Grande do Norte, 2004. [CD-ROM].

OLIVIERI, L. A importância históricosocial das Redes. In: Manual de Redes Sociais e Internet. Brasília: Centro de Direitos Humanos, 2017. Disponível em: $<$ http:/ / formacaoredefale.pbworks.com/f/ A $\% 20$ Import $\%$ C3 $\%$ A2ncia $\% 20$ Hist $\%$ C $3 \%$ B3rico-social $\% 20$ das $\% 20$ Redes.rtf $>$. Acesso em: 28 maio 2017.

PARANHOS, W. M. M. R. Fragmentos metodológicos para projetos e execução de gestão informatizada de coleções de documentos e serviços em bibliotecas. Encon- 
tros BIBLI: revista eletrônica de Biblioteconomia e Ciência da Informação, Florianópolis, n. Especial, $2^{\circ}$ sem., p. 14-32, 2004. Disponível em:

$<$ https://periodicos.ufsc.br/index.php/eb/ article/view/1518-2924.2004v9nesp2p14/

5488>. Acesso em: 20 maio 2017.

PASSETTI. R. et al. Intensive dairy farming systems from Holland and Brazil: SWOT analyse comparison. Acta Scientiarum.

Animal Science, Maringá, v. 38 n. 4, out./dez. 2016. Disponível em:

$<$ http://www.scielo.br/scielo.php?script=sc i_arttext\&pid=S1807-

$86722016000400439 \& \operatorname{lng}=$ pt\&nrm $=$ iso $>$.

Acesso em: 05 out. 2017.

RAMOS, C. et al. Imagem e percepção humana: alternativa aplicada na classificação da literatura infanto-juvenil de uma biblioteca escolar. Perspectivas em Ciência da Informação, Belo Horizonte, v. 16, n. 4, p. 5572, out./dez. 2011. Disponível em $<$ http://www.scielo.br/pdf/pci/v16n4/v16 n4a06.pdf> Acesso em: 10 jun. 2017.

SABBAG, O. J.; COSTA, S. M. A. L. Strategic planning for dairy cattle: SWOT analysis applied to a property of a farmers' association in Dracena, São Paulo state, Brazil. Interações, Campo Grande, v. 16, n.1, jan./jun. 2015. Disponível em: $<$ http://www.interacoes.ucdb.br/article/vie w/95/128>. Acesso em: 03 out. 2017.

TANUS, G. F. S. C. As correntes de pensamento das Ciências Sociais e Humanas: enlace com a Biblioteconomia. Ciência da Informação em revista, Maceió, v. 4, n. 1, p. 3-16, jan./abr. 2017. Disponível em $<$ http://www.seer.ufal.br/index.php/cir/art icle/view/2872/2454> Acesso em: 02 jun. 2017.

TONIN, J. H. C.; SOUZA, E. D. A seleção de fontes de informação em bibliotecas prisionais do estado de alagoas: do direito às condições de acesso à informação do usuário apenado. Ciência da Informação em revista, Maceió, v. 1, n. 1, p. 47-63, jan./abr.
2014. Disponível em

$<$ http://www.seer.ufal.br/index.php/cir/art icle/view/1303/904 >Acesso em: 10 jun. 2017.

SILVA, C. R.; ARAUJO, N. C. Bibliotecas do Município de Capela, Alagoas: condições de acesso à informação e inclusão social.

Ciência da Informação em revista, Maceió, v. 3, n. 3, p. 20-35, set./dez. 2016. Disponível em:

$<$ http://www.seer.ufal.br/index.php/cir/art icle/view/1422/2102>. Acesso em: 03 out. 2017.

SILVA, M. A.; NEVES, R. J.; NEVES, S. M. A. S. Possibilidades de incorporação do processamento do cumbaru do assentamento Facão, Furna São José, na cadeia produtiva do turismo rural: estudo de caso na fronteira Brasil/Bolívia. Interações, Campo Grande, v. 17, n. 4, out./dez. 2016. Disponível em: $<$ http://dx.doi.org/10.20435/1984-042x2016-v.17-n.4(04)>. Acesso em: 03 out. 2017.

SOUZA, A. M. O coaching na atuação do profissional da informação. 2013. Dissertação (Mestrado em Cultura e Informação) Escola de Comunicações e Artes, Universidade de São Paulo, São Paulo, 2013. Disponível em:

<www.teses.usp.br/teses/disponiveis/27/2 7151/tde-18112013/pt-br.php>. Acesso em: 03 out. 2017.

UFRN. Sobre a UFRN. Natal: Universidade Federal do Rio Grande do Norte, 2017.Disponível em: $<$ http://www.ufrn.br/institucional/sobre-aufrn>. Acesso em: 22 abr. 2017.

UFRN. Resolução $\mathbf{N}^{\circ} \mathbf{1 4}$, emitida pelo Conselho Universitário da UFRN, em 02 de maio de 1959.

UFRN. Resolução n $^{\circ}$ 004/2013, emitida pelo Conselho Universitário da UFRN, em 05 de abril de 2013.

UFRN. SISBI. Histórico. Natal: Universidade Federal do Rio Grande do Norte, 2017. 
Disponível em:

$<$ http://www.sisbi.ufrn.br/pagina.php?a=hi storico>. Acesso em: 22 abr. 2017.

WERTHEIN, J. A sociedade da informação e seus desafios. Ciência da Informação, Brasília, v. 29, n. 2, p. 71-77, 2000. Disponível em:

$<$ http://www.scielo.br/pdf/ci/v29n2/a09v 29n2.pdf>. Acesso em: 03 out. 2017.
ZAMITE, A. I. S. A usabilidade do formulário de catalogação do sistema de automação de biblioteca: Biblivre. Ciência da Informação em revista, Maceió, v. 3, n. 3, p. 3646, dez. 2016. Disponível em: $<$ http://www.seer.ufal.br/index.php/cir/art icle/view/2631>. Acesso em: 03 out. 2017. 